\title{
Bilateral Renal Dysplasia
}

National Cancer Institute

\section{Source}

National Cancer Institute. Bilateral Renal Dysplasia. NCI Thesaurus. Code C101313.

A finding of congenital malformations in both kidneys characterized by the presence of cysts of various sizes, primitive ducts, islands of metaplastic cartilage and undifferentiated mesenchyme, and the absence of cortico-medullary demarcation. 